\title{
The role of design and visualization of handouts in the process of training personnel for the agro-industrial complex
}

\author{
Anna Mokina, ${ }^{1, *}$, Lubov Khoronko ${ }^{2}$ \\ ${ }^{1}$ The Southern Federal University, 105\42, B. Sadovay, 344006, Rostov-on-Don, Russia \\ ${ }^{2}$ The Don state technical University, 1, sq. Gagarina, 344003, Rostov-on-Don, Russia
}

\begin{abstract}
Today, the educational process is closely related to informatization, digitalization and visualization of educational information. The article discusses the role of graphic design in the training process, especially in the agro-industrial complex. The task is to track how the effectiveness of pedagogical activity depends on the quality of visualization of the submitted material, especially handouts. There are also considered the issues of structuring educational material for training future staff of the agricultural complex. As a successful factor in training future specialists, the principle of visual and graphic accessibility of educational material, the principle of a harmonious set of text and illustrative materials that provide a high level of training, including in the process of independent work of the student, should be laid down. The article deals with the issue of interactive communication through a handout, which also develops the communicative ability of students. Training is a dialogue between the teacher and the student, which is also influenced by the quality of the design of the submitted information, especially illustrative information. The use of interactive, multimedia and visual technologies allows us to take into account the personal and individual characteristics of students
\end{abstract}

\section{Introduction}

The development of society, information technologies, and scientific and technological progress affect all areas of activity, including the process of training highly qualified professionals and specialists who are ready for productive and innovative work, including the country's agro-industrial complex. Modernization of the educational process does not bypass the printing aspects and the quality of printed materials used in the training process. The professional pedagogical community is faced with the task of producing high-quality textbooks, study guides, including handouts: brochures, tests, maps, reference graphics, notebooks, maps, tables, didactic visual study guides, etc. The process of forming a modern textbook and educational literature is a process of collaboration of pedagogy, psychology, sociology, art history, various sciences, and, of course, graphic design and printing. In the modern educational space, both printed and electronic forms of educational publications,

\footnotetext{
Corresponding author: aymokina@list.ru
} 
including SWOT analysis [1], are equally in demand. A textbook and handout is a textual and visual reflection of the curriculum. it is a means and technology of learning that develops, including student independent work and self-study. In their works, issues of design of printed publications and the use of fonts (printing types) in the text were raised by A.R. Nikitin, K.S. Kuzminsky, issues of graphic design of books and educational publications can be reflected in the works of G.G. Guillot, D.V. Constaninov, L.I. Hessen, V.V. Pakhomova, B.M. Kissina and others, where the authors described the specifics of illustrating books in the process of publishing. The collective work «Artistic design and design of a book» reveals the problem of forming a book as a complex of functional and compositional unity. Questions about the design of educational and school literature were raised in the book «On the artistic construction of textbooks» and «Manuscript - art editor» by V.I. Ryvchin and in V.A. Andreeva's thesis research «Design of the alphabet of ABC books in Russia (artistic and technical design of alphabets and ABC books: the history of modern practice)». Methodological issues on visualization of educational literature and manuals were considered by such figures as Y.A. Komensky, M.I. Makhmutov, and K.D. Ushinsky in their scientific search. Questions of the theory of graphical-visual research and design were raised in their works by K. Mamardashvili, S.V. Aranova and A.A. Verbitsky, as well as foreign researchers Ronald B. Larson [2] and others.

In the modern scientific and pedagogical discussion, scientists introduce two concepts of handout images: "graphical» and «visual», where «graphical» is a synonym for the concept of «demonstrative» - the teacher literally demonstrates the schedule, process, and object in pictures. The concept of «visual» includes an associative and figurative representation of the image, which encourages reflection, comprehension and figurative representation. Visualization in the educational process is the transfer and display of the ideological meanings of the content in the image. In such a situation, the way of thinking can be explicated and serve as the basis for both the students' thinking and applied processes [3].

\section{Materials and Methods}

The study used empirical research methods: the study of the experience of educational organizations in the sector of training of agro-industrial complex in Rostov-on-don, pedagogical supervision and normative and educational documentation, as well as theoretical methods: analysis, generalization.

\section{Experimental base of the study}

The base of the experimental research is the Federal state budgetary educational institution of Higher education «Don State Technical University».

The process of development and change of information technologies is rapid, but this professional and technological change is reflected in the scientific and pedagogical environment, especially when developing handouts and educational and methodological support for the educational process. Such modern tools, technologies and graphic design can attract the attention of students to obtaining knowledge, cognitive motivation, aesthetics and fascination of educational materials and put graphical and visual accents. High-quality accompanying material allows you to attract attention in the psychological and pedagogical environment, almost at a high level to maintain a high level of cognitive interest, which in turn leads to the development of the student's thinking as a whole [4].

It has been scientifically proven that people are more likely to remember visual information, graphic symbols and signs. In this regard, the modernization of the educational 
process in the field of visualization of educational information is relevant and in demand. As the educational process and the submitted material become more complex, the volume of illustrative material is more advanced than text information. But today, little is said about how to correctly and easily present graphical and visual information based on visual aspects, color, color psychology, selected font, line thickness, etc. For effective work of the teacher with handouts and visualization of educational information in accessible and modern ways, it is necessary to determine a number of knowledge, methods and requirements for providing illustrative support of educational information used in professional activities. When working on the visualization of both handouts and educational literature, it is necessary to build a comprehensive and step-by-step algorithm of actions that will determine the success of the final result, both the material design and the entire training as a whole. Such an algorithm for designing handouts is comparable in importance to the publication of advertising products to promote the product in the world of marketing. Algorithm design during our study was divided into several stages: preparation, which includes goals and objectives, creating illustrations, diagrams, etc., and forming, directly creating the visual design of handouts. The method of illustrative support of the training process consists in determining certain positions related to the purpose, function and purpose of images: training, accentuating, informative, complementary, reference, etc. also, images which may differ in technique: conditional, graphic, color, photo fixation, drawn, tables, graphs, diagrams, formulas, combined images.

A handout in the field of pedagogical activity is a set of educational and methodological materials that are used by future specialists in the course of training, as well as in the course of independent work by students. Graphic design, legibility, clarity, relatability, accessibility, and quality of printing are important conditions and requirements for the effectiveness of the educational process using handouts. Such a set of materials has communicative tasks and functions.

If we trace the historical process of education, we can say that the first samples of handouts are not literally connected with printing and were invented before it was patented. These include the papyrus scrolls of the Ancient world and the Mesopotamian glyptic, which were used to transmit illustrative and educational information, including educational information - the first samples of handouts that arose in the BC. But such visual products were actively developed at the time of the creation of the printing press. Modern society cannot be imagined without printed materials, especially teaching activities.

The study identified the positions and requirements without which the creation of handout visual material will not be effective. It is necessary to include:

- clarity and understanding of conventional signs;

- the illustrational objects that represent the information needs to be associated and to reflect through graphic images of the presented data;

- carry a useful and productive information and visual load;

- colorful to carry, but a clear load;

- have a clear saturation and tonal solution.

For the successful effect of the handout design for the educational process, including training for the agro-industrial complex, it is necessary to know the basics of psychology, semantics and the influence of color on the viewer, the visual perception of fonts at different scales of information presentation, etc. If at least one of the requirements was not taken into account when creating a visual handout, then, for example, due to the wrong choice of font, its size and color, or the selected bad printing material (paper quality, dyes), there is a poor perception of the submitted educational information, as well as its distortion in perception. A high-quality graphic image is formed in a sequential visual series and allows you to improve the quality of the handout [5]. 
Color in the handout is one of the important aspects of effective perception of information by students, its memorization and emphasis in the process of learning in the classroom and in the course of independent work, which is an integral part of the entire educational process. Thoughtful and competent use of color and its perception in the design of the handout leads to the effective result for all participants of pedagogical and educational activities, both teacher and student. Color is a strong element of any composition, including printed educational products. It can evoke the most contradictory emotions, feelings, and associations, and is the language of nonverbal communication and information transfer [6]. Psychological studies have shown that color associations are perceived subjectively, depending on the upbringing, culture and aesthetics of the individual. In their research and tests, Tibor S. Balint [7], Anthony Freeman [7], Andrina Granić [8], Charles Mifsud [8], Maja Čukušić[8], Federico Pierotti [9], Carolina Reta, Ismael Solis-Moreno, and Jesus A. have raised questions about the influence of color in advertising, print and electronic visualization and learning tools. Gonzalez, Rogelio Alvarez-Vargas, Nery Delgadillo-Checa [10], L. M. Matveecheva, E. O. Filinkova and others.

In color science, there are several definite and stable associations about the influence of color, so cold tones are removed, and warm ones are «protruding». So Jungsil Choi David, Yexin Jessica Li, Priyamvadha Rangan, Bingqing Yin Miranda, Surendra N. Singh [11] in their study, conduct a number of experiments on the influence of warm and cold colors on behavior, perception and personality psychology. Color is one of the means of communication and one of the main factors influencing the viewer, and this also applies to the educational process. When creating a visual handout in the learning process, it is necessary to take into account the fact that any color has a tone, saturation, optical density, and even spatial qualities. The saturation, density, and monochrome of illustrations in both print and digital formats is an important factor in the quality of the created handout kit (Figure 1).
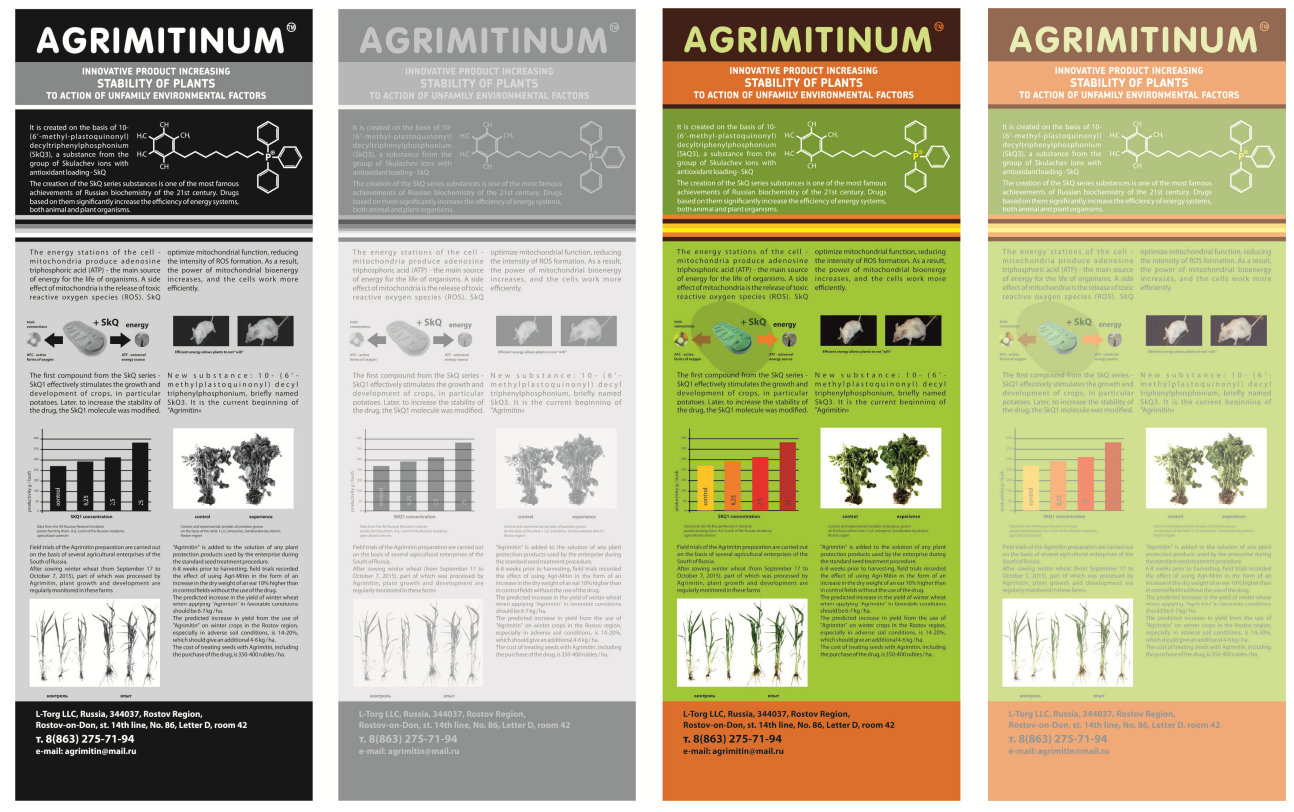

Fig. 1. Demonstration of color saturation and monochrome. Designer A.V. Kireev.

The choice of color is a difficult issue even in our daily life, especially in educational activities, due to the powerful influence of color. Bright infographics make a person 
emotionally perceive the objects, thanks to the symbolic content can act on the subconscious. The study revealed the relationship between font size, image size, line thickness, background color, and font. For example, to highlight the topic title and decorative elements during the presentation of information on the handout or digital slide of the presentation in the classroom, you must use contrasting infographics and additional colors. And teacher in the process of creating design illustrations for your lesson or training tasks for independent work of the student is to apply text visualization but also visual, is the right combination leads to efficiency inherent in the goals and objectives of the discipline (Figure 2).
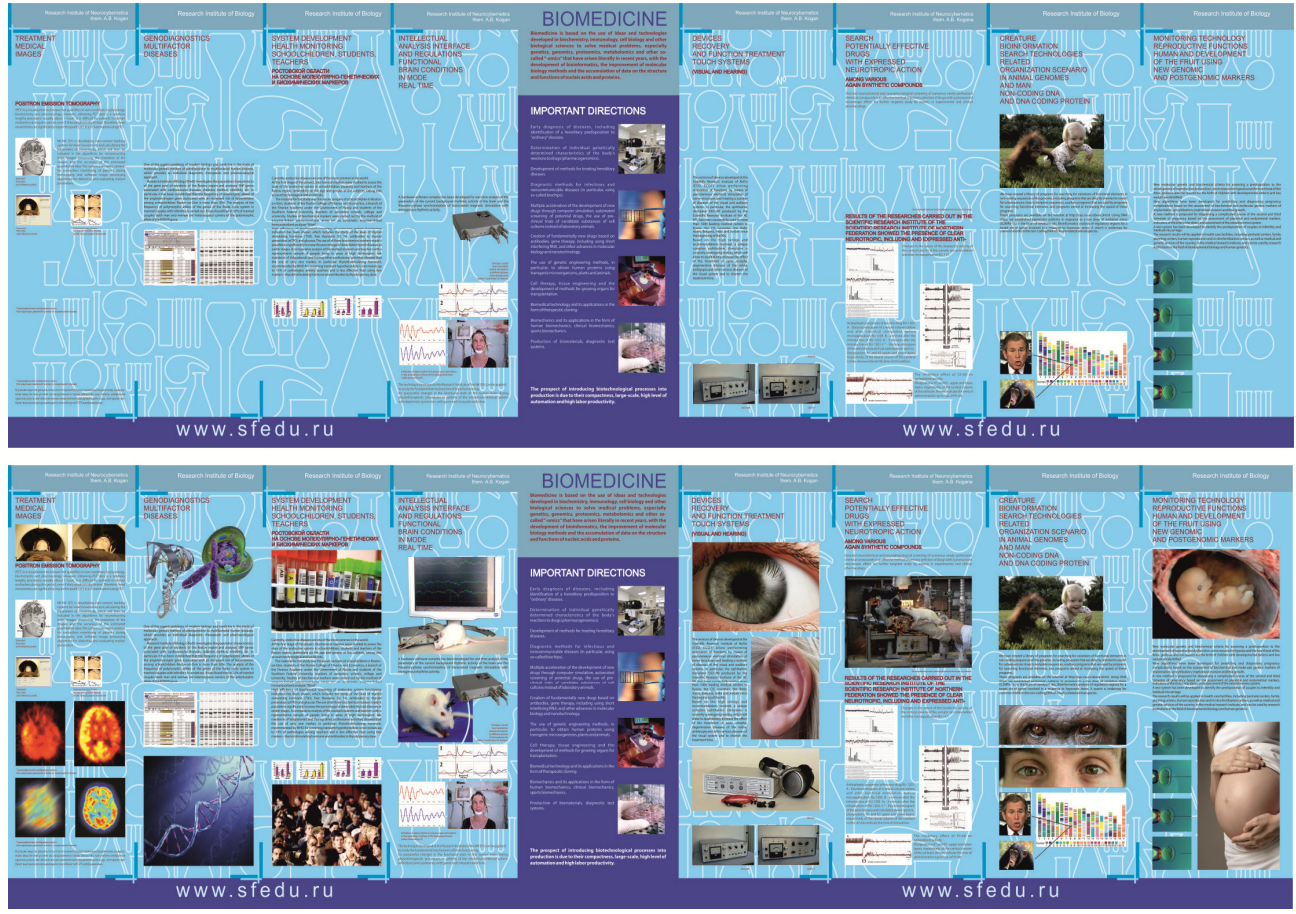

Fig. 2. Handout with text and images. Designer A.V. Kireev.

These questions are raised in their research [12] on the example of digital graphic information used in the development of virtual smartphone applications. It can be argued that the design, background color, spacing between lines and paragraphs, font size and line thickness are just as important in the visualization process as the sense and concern embedded in this illustration.

One of the most desired and popular background colors can be called blue, because it is the color of nobility, tranquility and harmony, to a greater extent it causes positive emotions, "smart color». Red is a bright color, on the contrary, the color is a slogan and a call. According to A. Hurlbert, Y. Ling, it is necessary «to take into account the importance of behavioral use of color and the known perceptual and physiological properties of color vision, it is likely that the preference for colored objects leads to a preference for the colors themselves. The underlying universality of human color preference patterns (liking blue, disliking yellow and yellow-green) supports the idea of evolved emotional responses to color» [13]. So, each color has its own associations, which should be taken into account by the teacher when forming the handout. Blue and red are alternative colors, they are quite bright and are not associated with negative impressions. Each spectral color has an effect on the human body, causes a visual reaction, make a person react, feel and perceive. In the 
professional environment, such a concept as «color associations» was introduced. «At every stage of printing production, color is one of the most important and undoubtedly powerful elements of composition» [14].

Digital technologies carry the maximum load on the quality of handouts. Today, when inkjet and laser printing techniques in one pass maximum polychrome pictures and images [15] allows you to enable the most realistic illustration made with the use of information systems based on GIS technologies that makes it possible to demonstrate, for example, the configuration of fields and their area of spreading, the direction of plowing, etc.

\section{Conclusions}

To create an effective handout of visual material used in the process of training agroindustrial complex, the teacher must take into account several factors and apply a number of requirements: color, scale, shape, clarity of the image, the ratio of the scale of text and images, color saturation and brightness, its associative influence. It is difficult to overestimate the importance of proper use of color in the handout training material - a small emphasis and the information provided is securely fixed in the student's mind, and excess brightness and over polychrome will lead to a loss of attention, as well as distract from the essence and main idea of the lesson. «Today's technological tools provide new opportunities for visualization of educational material», in this connection, we can highlight a number of aspects that make the design and visualization of the handout successful: distinctness and clarity of the image; effective design; readability of the text; emotional and associative colors; high-quality diagrams, tables, diagrams; selection of the scale of the ratio of text, symbol and images; visualization; simplification of illustrations; accessibility of image understanding; quality of photos and printed materials.

\section{References}

1. E.N. Merkulova, GESJ: Education Science and Psychology 5(42), 13-20 (2016)

2. R.B. Larson, Computers and education 53(4), 1278-1284 (2009)

3. V. Poghosyan, Wisdom 7(2), 162-166 (2016)

4. A.Y. Karymsakova, Z.A. Kutpanova, Eurasian Union of Scientists (ESU) 3(48), 26-31 (2018)

5. O.I. Vorozheikina, U.V. Pak, Collection of materials of the International scientific and practical conference (Academy of marketing and social and information technologiesIMSIT, Krasnodar, 2017)

6. H. Zijun, Grand Altai research \& Education 2, 122-124 (2018)

7. T.S. Balint, A. Freeman, Acta Astronautics 137, 182-191 (2017)

8. A. Granić, C. Mifsud, M. Čukušić, Computer education 53(4), 1052-1081 (2009)

9. F. Pierotti, Emotions, technology and design. Emotions and technologies, 3-18 (2016)

10. C. Reta, J.A. Cantoral-Ceballos, I. Solis-Moreno, J.A. Gonzalez, R. Alvarez-Vargas, N. Delgadillo-Checa, Journal of visual communication and image representation 54, 39-50 (2018) https://doi.org/10.1016/j.jvcir.2018.04.009

11. D. Jungsil Choi, J. Yexin Li, R. Priyamvadha, M. Bingqing Yin, S.N. Singh, International journal of marketing research https://doi.org/10.1016/j.ijresmar.2020.02.001

12. J. Grobelny, R. Michalski, Computers in human behavior 43, 85-100 (2015) https://doi.org/10.1016/j.chb.2014.10.036 
13. A. Hurlbert Y. Ling, Color Design (Second Edition) Theory and applications. Woodhead publishing series in textiles, 169-192 (2017) https://doi.org/10.1016/B9780-08-101270-3.00007-2

14. G.S. Glebova, Postulate 4(42), 28 (2019)

15. C. Parraman, Color Design (Second Edition). Theories and applications. Woodhead publishing series in textiles, 589-618 (2017) https://doi.org/10.1016/B978-0-08101270-3.00025-4 